\title{
PROFILE OF ACUTE CORONARY SYNDROME IN YOUNG PEOPLE: A HOSPITAL BASED OBSERVATIONALSTUDY IN WESTERN NEPAL
}

\author{
Paudel $N^{1^{*}}$, Alurkar VM ${ }^{2}$, Jha $G S^{3}$, Kafle $R^{3}$, Sapkota $S^{4}$, Lamsal $L^{5}$
}

\section{Affiliation}

1. Consultant Cardiologist, Department of Cardiology, Manipal College of Medical Sciences, Pokhara, Nepal

2. Professor, Department of Cardiology, Manipal College of Medical Sciences, Pokhara, Nepal

3. Lecturer, Department of Cardiology, Manipal College of Medical Sciences, Pokhara, Nepal

4. Lecturer, Department of Internal Medicine, Manipal College of Medical Sciences, Pokhara, Nepal

5. Resident, Department of Internal Medicine, Manipal College of Medical Sciences, Pokhara, Nepal

\section{ARTICLE INFO}

\section{Article History}

Received : 26February, 2018

Accepted : 29 March, 2018

Published : 30 April, 2018

(c) Authors retain copyright and grant the journal right of first publication with the work simultaneously licensed under Creative Commons Attribution License CC - BY 4.0 that allows others to share the work with an acknowledgment of the work's authorship and initial publication in this journal.

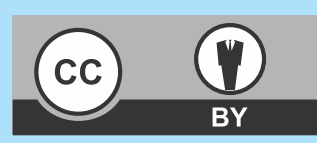

ORA 57

\section{DOI: http://dx.doi.org/10.3126/bjhs.v3i1.19759}

\author{
* Corresponding Author \\ Dr. Navaraj Paudel \\ Consultant Cardiologist \\ Manipal College of Medical Sciences, Pokhara, Nepal \\ Email: paudeldrnavarajdm@gmail.com \\ https://orcid.org/0000-0003-4551-0808
}

\section{Citation}

Paudel N, Alurkar VM, Jha GS, Kafle R, Sapkota S, Lamsal L. Profile of Acute Coronary Syndrome In Young People: A Hospital Based Observational Study in Western Nepal. BJHS 2018;3(1)5 : 361-365.

\section{ABSTRACT}

\section{Introduction}

Acute coronary syndrome is associated with high mortality and morbidity. The incidence of acute coronary events in young is increasing.

\section{Objectives}

This study aimed at evaluating the profile of acute coronary syndrome in young people in the western part of Nepal.

\section{Methodology}

A retrospective study was designed. All patients admitted for acute coronary syndromes were taken and data of acute coronary syndrome involving patients aged less than 45 years from April 2015 through December 2017 were collected in a pre-structured proforma and analyzed.

\section{Results}

There were 712 (489 males and 223 females with $M: F=2.19: 1)$ acute coronary syndrome patients admitted during the study period. Only $79(12.9 \%)$ patients were patients $<45$ years of age. Commonest risk factor of acute coronary syndrome was smoking $(69 \%)$ followed by dyslipidemia (46.8\%), hypertension (45.5\%) and diabetes (14\%). Out of 79 patients of young acute coronary syndrome, 37 (46.8\%) presented with ST elevated myocardial infarction, 16 (20.2\%) with non-ST elevated myocardial infarction and $26(32.9 \%)$ with unstable angina. Most common finding in coronary angiography was single vessel disease (35\%) -left anterior descending artery being the commonest (53\% of single vessel disease), double vessel disease (17.7\%), non-critical coronary artery disease (16.4\%), triple vessel disease (7.6\%) and left main (1.2\%). Myocardial bridging was seen in $1.2 \%$ and $20 \%$ had normal coronaries. Comparison of males and females in different categories of acute coronary showed that males predominate significantly in ST elevated myocardial infarction (odds ratio: $2.99 ; p=0.03$ ) but there was no significant difference between the males and females presenting either with Non ST elevated myocardial infarction or unstable angina.

\section{Conclusion}

Acute coronary syndrome in young people was common (12.9\%) particularly males with Non ST elevated myocardial infarction. Smoking was the commonest risk factor. Public awareness regarding stoppage of cigarette smoking should be focused to prevent such events especially in the young population.

\section{KEYWORDS}

Acute coronary syndrome, smoking, young 


\section{INTRODUCTION}

Acute coronary events and ischemic heart disease (IHD) are considered as one of the most common cause of death in the world. ${ }^{1}$ Acute coronary syndrome (ACS) is a clinical spectrum of the ischemic heart disease that includes unstable angina (UA), non-ST segment elevation myocardial infarction (NSTEMI) and ST segment elevation myocardial infarction (STEMI). ACS in older population ( $>45$ years in male and $>55$ years in female) is relatively higher than younger population. ${ }^{2}$ The prevalence of ACS among population less than 45 years of old (considered as young ACS) is 2 to $10 \%$ in studies conducted from different parts of world. ${ }^{2-9}$ There are few studies in Nepal regarding ACS in young with a prevalence of $8.8-11 \% .{ }^{10-11}$

Cardiovascular risk factors, such as smoking, dyslipidemia, obesity, and family history of coronary artery disease (CAD), have been seen as more frequent among young ACS in these studies. ${ }^{2 \cdot 11}$ Not only this, there are different theories behind the exact pathophysiology of ACS as different other etiologies and novel risk factors like homocysteinemia may be implicated than older population. The extent of coronary involvement, the clinical presentation, and clinical outcome also differs from older population..$^{12-15}$ The aim of this study was to find out the extent of this problem and also to describe its possible correlates.

\section{METHODOLOGY}

This is a retrospective study conducted at Manipal College of Medical Sciences-Teaching Hospital, Pokhara, Nepal. After clearance from the institutional ethical board, the study population for the present analysis was selected from the records of inpatients with ACS who presented in the hospital between April 2015 to Dec 2017. Inclusion criteria involved were all patients admitted for STEMI, NSTEMI or UA more than 18 years and $\leq 45$ years of age. The term ACS refers to any group of clinical symptoms compatible with acute myocardial ischemia and includes UA, NSTEMI and STEMI.

Medical records were reviewed which included proper medical history, drug abuse, smoking, physical examination, lipid profiles, 12-lead electrocardiogram (ECG), echocardiography. coronary angiography(CAG) and percutaneous coronary intervention ( $\mathrm{PCl})$ data were taken as per availability. Dyslipidemia was defined in accordance with the reports of the National Cholesterol Education Program (Adult Treatment Panels II and III). ${ }^{16}$

Data were collected in a preformed proforma and analyzed in SPSS software version 16. The significant difference between two groups was compared using ANOVA. Odds ratio was calculated for required appropriate values and $p$ values were considered significant at a predetermined significance level of $5 \%$.

\section{RESULTS}

Total number of patients admitted and treated for the diagnosis of ACS was 712. Out of them 489 were males and 223 were females. The male to female ratio was 2.19:1. Among these 79 (12.9\%) patients were admitted for STEMI, NSTEMI or UA more than 18 years and $\leq 45$ years of age.

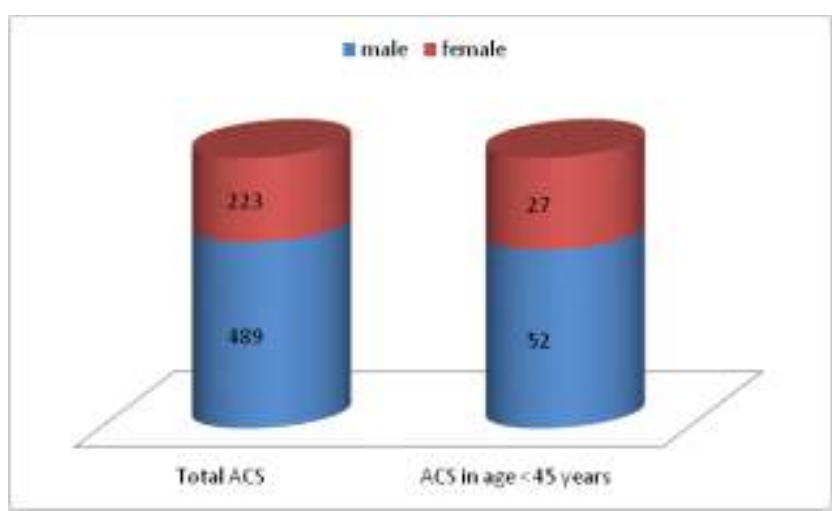

Figure 1: Sex Distribution of ACS

On further analysis of patients with ACS under 45 years of age, 52 patients were male while 27 patients were female (Figure 1). Figure 2 shows pattern of sex distribution of patients with ACS in further subdivision with age.

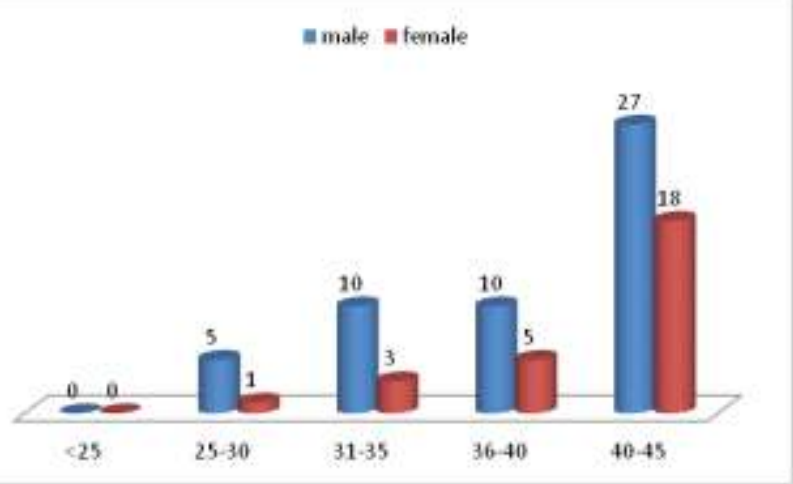

Figure 2: Sex distribution of patients with ACS in further subdivision with age.

Out of 79 patients of young ACS patients, 37 (46.8\%) presented with STEMI, 16 (20.2\%) presented with NSTEMI and $26(32.9 \%$ ) presented with UA (Table 1 ).

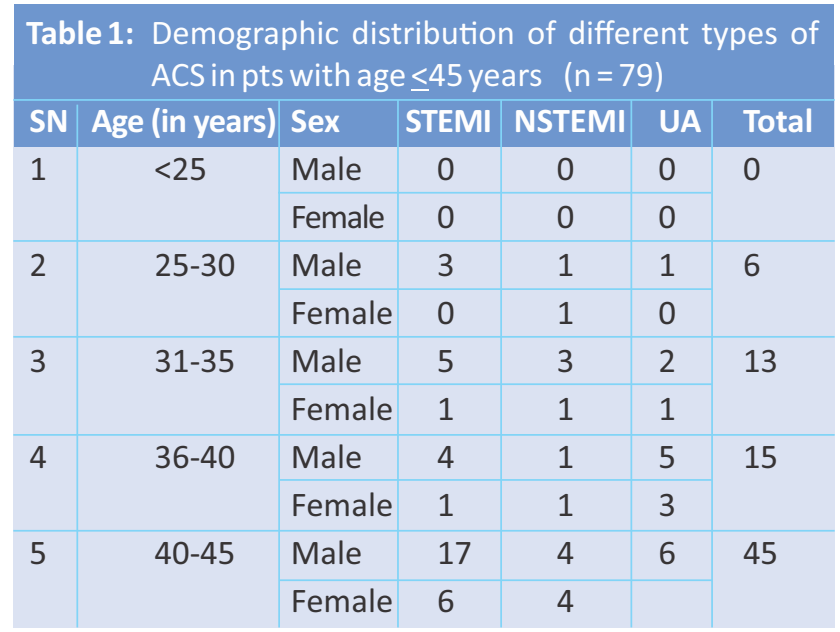


Further comparison of males and females in different categories of ACS was done. This showed that males predominate significantly in STEMI but there was no significant difference between the males and females presenting either with NSTEMI or UA (table 2 ).

All 79 cases of ACS underwent CAG. Most common finding in CAG was single vessel disease (SVD) (35\%) -left anterior descending artery (LAD) was the commonest (53\% of SVD). Next common finding was double vessel disease (DVD) $(17.7 \%)$, followed by non-critical coronary artery disease (CAD) (16.4\%), triple vessel disease (TVD) (7.6\%) and left main (1.2\%). Myocardial bridging was seen in $1.2 \%$ and $20 \%$ had normal coronaries (Table 3 ).

\section{DISCUSSION}

Patients with symptoms of ACS are very common in emergency departments. There is growing incidence and prevalence of acute coronary syndrome in young adults. The major patho-physiologic mechanism is either plaque rupture or fissuring with superimposed thrombus. Today, ACS is one of the commonest causesof hospitalization. The prevalence of ACS among population less than 45 years of age (considered as young ACS) is 2 to $10 \%$ in studies conducted from different parts of world. ${ }^{2-9}$ There are few studies in Nepal regarding ACS in young with a prevalence of $8.8-11 \% .{ }^{10-11}$ Our study showed $12.9 \%$ patients with age less

Table 2: Comparison of males and females presenting with STEMI, NSTEMI and UA in pts with age $\leq 45$ years

\begin{tabular}{|l|c|c|c|}
\hline Variable & No of pts with STEMI & Odds ratio & P-value (2-tailed Fischer exact test) \\
\hline $\begin{array}{l}\text { Male }(n=52) \\
\text { Female }(n=27)\end{array}$ & 29 & $2.99(1.11-8.06)$ & 0.03 \\
\hline Variable & 8 & & \\
\hline Male $(n=52)$ & 9 & Odds ratio & P-value (2-tailed Fischer exact test) \\
\hline Female $(n=27)$ & 7 & $0.59(0.19-1.83)$ & 0.39 \\
\hline $\begin{array}{l}\text { Variable } \\
\text { Male }(n=52)\end{array}$ & No of Pts with UA & Odds ratio & \\
\hline Female $(n=27)$ & 14 & $0.46(0.17-1.22)$ & P-value (2-tailed Fischer exact test) \\
\hline
\end{tabular}

\section{Table : 3}

\section{SN CAG findings}

Number Percentage

1 Single vessel disease
(LAD)

28

2

Double vessel

disease (DVD)

\section{4}

6

Total 50 patients underwent $\mathrm{PCI}$ (at least culprit vessel in all
the STEMI), 6 patients of NSTEMI and 7 patients of UA
underwent $\mathrm{PCI}$. Commonest risk factor for CAD was
smoking $(69 \%)$ followed by dyslipidemia $(46.8 \%)$,
hypertension( $45.5 \%$ ) and diabetes (14\%).

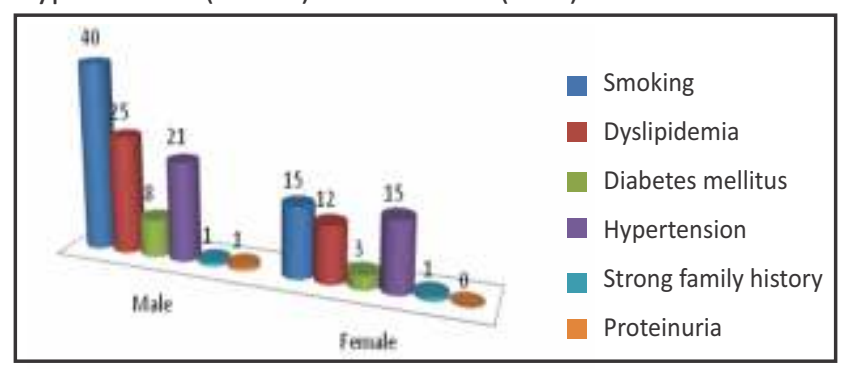

Figure 3: Risk Factors of ACS than 45 years which is slightly higher than other parts of world but regarding Nepal, study done by Laudari $\mathrm{S}^{10}$ showed $11.11 \%$ in patients with age less than 40 years. ${ }^{11}$ There is increasing trend of ACS in young as noted from same clinical setting in different frame of time too. ${ }^{10,11}$ Not only young males, young females have also been seen presenting with rising trends of ACS in this study. The older measurements may be the 'tip of the iceberg' since young asymptomatic patients usually do not undergo medical investigations due to low suspicion unless the disease is very severe as stated by Romboldt et al. ${ }^{17}$

Smoking is the commonest risk factor in this study (69\%) followed by dyslipidemia (46.8\%), hypertension (45.5\%) and diabetes (14\%). There are literatures reporting smoking by up to $82 \%$ of young patients suffering from ACS. ${ }^{18}$ Case control studies showed that smoking is an independent risk factor for the development of ischemic heart disease in young patients. ${ }^{19}$ Smoking persistence is associated with the occurrence of secondary events after $\mathrm{MI}$ in young patients. A study showed that decreased left ventricular ejection fraction at presentation and the continuation of smoking after myocardial infarction were most predictive for further MACEs in young patients. ${ }^{20}$ Taken together, it shows importance of stopping smoking in the primary and secondary prevention of ACS specifically in these individuals.

In this study, risk factors like dyslipidemia and hypertension were also found to be higher ( $46 \%$ and $45 \%$ each). We know 
that hypertension and dyslipidemia are considered as conventional risk factors. Various studies shows hypertension in $30-50 \%$ of individuals with ACS. $^{21-23}$ In a study done in central Nepal, hypertension was found in $58 \%$ of young ACS and dyslipidemia in $24 \%$ of cases. ${ }^{10}$ Dyslipidemia (mainly high LDL and low HDL) along with metabolic syndrome were also seen in significant numbers in patient with ACS in a study by Yagi $\mathrm{H}$ in Japan. This study also suggested smoking as a crucial risk factor among all other risk factors in cases of ACS as compared to stable CAD. ${ }^{21}$ Risk factors like diabetes is associated with multivessel disease and poor prognosis. ${ }^{24}$ In our study diabetes was seen in $14 \%$ of individuals which is comparable to a study done in central Nepal. ${ }^{10}$

In this study, all 79 cases of ACS underwent CAG. Most common finding in CAG was SVD (35\%) -LAD was the commonest (53\% of SVD), DVD (17.7\%), non-critical CAD $(16.4 \%)$, TVD $(7.6 \%)$ and left main (1.2\%). Myocardial bridging was seen in $1.2 \%$ and $20 \%$ had normal coronaries. These findings are similar to findings shown by Colkesen et al. ${ }^{25}$ where LAD was the commonest vessel involved in young STEMI patients with $\leq 35$ years of age followed by RCA, LCX, and LMCA.

In the current study, out of 79 patients of young ACS patients 37 (46.8\%) presented with STEMI, 16 (20.2\%) presented with NSTEMI and 26 (32.9\%) presented with UA.Further comparison of males and females in different categories of ACS was done. This showed that males predominate significantly in STEMI but there was no statistically significant difference between the males and females presenting either with NSTEMI or UA. Parajuli $M$ et al also have shown that STEMI is significantly common in males than females. ${ }^{26}$ Hua et al from China and Andrea R from Brazil have also showed that males have higher incidence of STEMI, increased rates of hospitalization and complications associated with ACS than females. ${ }^{27,28}$

\section{REFERENCES}

1. WHO 2017. The top 10 causes of death. Available at: http:// www.who.int/mediacentre/factsheets/fs310/en.

2. Imazio M, Bobbio M, Bergerone S, Barlera S, Maggioni AP. Clinical and epidemiological characteristics of juvenile myocardial infarction in Italy: the GISSI experience. G ItalCardiol. 1998;28(5): 505-512. doi:https://doi.org/10.1253/circj.69.1454

3. Doughty M, Mehta R, Bruckman D, Das S, Karavite D, Tsai T, et al. Acute myocardial infarction in the young- the University of Michigan experience. Am Heart J. 2002;143(1):56-62.PMID: 11773912 .

4. Shiraishi J, Kohno Y, Yamaguchi S, Arihara M, Hadase M, Hyogo M, et al. Acute Myocardial Infarction in Young Japanese Adults Clinical Manifestations and In-Hospital Outcome. Circ J. 2005;69(12): 1454 -1458. PMID:16308491.

5. Avezum A, Makdisse M, Spencer F, Gore JM, Fox KAA, Montalescot $G$, et al. Impact of age on management and outcome of acute coronary syndrome: observations from the Global Registry of Acute Coronary Events (GRACE). Am Heart J. 2005;149(1):67-73. DOI: 10.1016/j.ahj.2004.06.003.

\section{CONCLUSION}

Acute coronary syndrome in young people was higher (12.9\%). Males predominate in all types but statistically significant predominance was seen in STEMI. Smoking was the commonest risk factor for ACS in young. Single vessel disease particularly left anterior descending artery was the commonest finding in coronary angiography. Public awareness regarding stoppage of cigarette smoking should be focused to prevent such events especially in the young population.

\section{RECOMMENDATIONS}

Larger prospective studies including conventional and novel risk assessment should be done to assess the actual data in the community as we have seen that the trend of young ACS has been increasing.

\section{LIMITATION OF THE STUDY}

This is a retrospective, single centered study so our analysis was limited by reliance on secondary source of data. Also conventional risk factors are only considered but novel risk factors like homocystenemia, thrombophilic conditions etc. could not be assessed due to unavailability of these tests and being retrospective study, we could not do much on it either.

\section{ACKNOWLEDGEMENT}

I thank Dr Prakash Thapa, assistant professor in Psychiatry for helping me to prepare this manuscript.

\section{CONFLICT OF INTEREST}

We declare no conflict of interest for preparing this manuscript.

6. Tungsubutra W, Tresukosol D, Buddhari W, Boonsom W, Sanguanwang S, Srichaiveth B. Acute coronary syndrome in young adults: the Thai ACS Registry. J Med Assoc Thai. 2007;90 (Suppl 1): 81-90. PMID:18431890.

7. Morillas P, Bertomeu V, Pabón P, Ancillo P, Bermejo J, Fernández C, et al. Characteristics and outcome of acute myocardial infarction in young patients. The PRIAMHO II study. Cardiology. 2006;107(4): 217-25. https://doi.org/10.1159/000095421.

8. Panduranga P, Sulaiman K, Al-Zakwani I, Abdelrahman S. Acute coronary syndrome in young adults from oman: results from the gulf registry of acute coronary events. Hear views Off J Gulf Hear Assoc. Medknow Publications; 2010;11(3):93. doi:10.4103/1995705X.76799.

9. Chen TS-C, Incani A, Butler TC, Poon K, Fu J, Savage M, et al. The Demographic Profile of Young Patients ( $<45$ years-old) with Acute Coronary Syndromes in Queensland. Hear Lung Circ. 2014;23(1):49-55. doi: 10.1016/j.hlc.2013.05.648.

10. Laudari S, DhungelS, Dubey L, Panjiyar R, Gupta M, Subramanyam G, et al. Acute coronary syndrome in the young Nepalese population with their angiographic characteristics. Journal of College of Medical Sciences, Nepal. 2017;13(2):235-40. doi:http://dx.doi.org/ 10.3126/jcmsn.v13i2.17147. 
11. Gautam $\mathrm{M}$ et al. Acute coronary syndrome in an intensive care unit of a tertiary care centre: the spectrum and coronary risk factors. J Nepal Med Assoc. 2013 Apr-Jun;52(190):316-21. PMID:24362653.

12. Ogawa $M$, Abe $S$, Saigo $M$, Biro $S$, Toda $H$, Matsuoka $T$, et al. Homocysteine and hemostatic disorder as a risk factor for myocardial infarction at a young age. Thromb Res. 2003;109:253-8. https://doi.og/10.1016/S0049-3848(03)_00242-1.

13. Ghosh K, Khare A, Shetty S. Fasting plasma homocysteine levels are increased in young patients with acute myocardial infarction from Western India. Indian Heart J. 2007;59:242-5. PMID: 19124933.

14. Patrizi R, Pasceri V, Sciahbasi A, Summaria F, Rosano GM, Lioy E. Evidence of cocaine related coronary atherosclerosis in young patients with myocardial infarction. J Am CollCardiol. 2006; 47:2120-2. https://doi.org/10.1016/j.jacc.2005.12.060.

15. Nikfardjam M, Graf S, Hornykewycz S, Zorn G, Huber- Beckmann R, Wojta J, et al. Homocysteine plasma levels in young patients with coronary artery disease. Relation to history of acute myocardial infarction and anatomical extent of disease. Thromb Res. 2001; 103:35-9. DOI: https://doi.org/10.1016/S0049-3848(03) 002421.

16. Third Report of the National Cholesterol Education Program (NCEP) Expert Panel on Detection, Evaluation, and Treatment of High Blood Cholesterol in Adults (Adult Treatment Panel III) final report. Circulation. 2002;106:3143-421. PMID: 12485966.

17. Rumboldt Z, Rumboldt M, Pesenti S, Polic S, Miric D. Peculiarities of myocardial infarction at young age in Southern Croatia. Cardiologia. 1995;40:407-11. PMID: 8640853.

18. Teixeira M, Sa I, Mendes JS, Martins L. Acute coronary syndrome in young adults. Rev Port Cardiol. 2010;29:947-55. PMID: 20964107.

19. Hbejan K. Smoking effect on ischemic heart disease in young patients. Heart Views. 2011;12:1-6. doi: 10.4103/1995-705X.81547.

20. Rallidis LS, Lekakis J, Panagiotakos D, Fountoulaki K, Komporozos C, Apostolou T, et al. Long-term prognostic factors of young patients (<or=35 years) having acute myocardial infarction: the detrimental role of continuation of smoking. Eur J CardiovascPrevRehabil. 2008; 15:567-71. https://doi.org/10.1097/HJR.0b013e3283077 4db.

21. Yagi $\mathrm{H}$, Komukai $\mathrm{K}$ et al. Difference in risk factors between acute coronary syndrome and stable angina pectoris in the Japanese: Smoking as a crucial risk factor of acute coronary syndrome. Journal of cardiology. 2010; 55(3): 345-53. doi: 10.1016/j.jjcc.2009.12.010.
22. A.M. Gotto Jr.Interactions of the major risk factors for coronary heart disease. Am J Med, 80 (1986), pp. 48-55. Doi: 1011-7571/0024-0199.

23. A.T. Hirsch, Z.J. Haskal, N.R. Hertzer, C.W. Bakal, M.A. Creager,J.L. Halperin, et al.ACC/AHA 2005 Practice Guidelines for the management of patients with peripheral arterial disease (lower extremity, renal, mesenteric, and abdominal aortic): a collaborative report from the American Association for Vascular Surgery/Society for Vascular Surgery, Society for Cardiovascular Angiography and Interventions, Society for Vascular Medicine and Biology, Society of Interventional Radiology, and the ACC/AHA Task Force on Practice Guidelines (Writing Committee to Develop Guidelines for the Management of Patients With Peripheral Arterial Disease): endorsed by the American Association of Cardiovascular and Pulmonary Rehabilitation; National Heart, Lung, and Blood Institute; Society for Vascular Nursing; TransAtlantic Inter-Society Consensus; and Vascular Disease Foundation. Circulation, 113 (2006), pp. e463e654. https://doi.org/10.1016/j.jacc.2006.02.024.

24. Pandey A, Darren K et al. Revascularization Trends in Patients With Diabetes Mellitus and Multivessel Coronary Artery Disease Presenting With Non-ST Elevation Myocardial Infarction. Circ CardiovascQual Outcomes. 2016;9:197-205. doi: 10.1161/ CIRCOUTCOMES.115.002084.

25. Colkesen AY, Acil T, Demircan S, et al. Coronary lesion type, location, and characteristics of acute ST elevation myocardial infarction in young adults under 35 years of age. Coron Artery Dis. 2008;19:3457. https://doi.org/10.1097/MCA.0b013e3283030b3b.

26. Parajuli M, Maskey A, Kohli SC, Shrestha UK. Gender difference in conventional risk factors in patients with acute coronary syndrome admitted in Manipal Teaching Hospital. Nepal Journal of Medical Sciences. 2012;1(1):31-34.http://dx.doi.org/10.3126/njms. v1i1.5794

27. Hung-Yu Yang, Jen-Hung Huang, Chien-Yeh Hsu, and Yi-Jen Chen, "Gender Differences and the Trend in the Acute Myocardial Infarction: A 10-Year Nationwide Population-Based Analysis," The Scientific World Journal, vol. 2012, Article ID 184075, 11 pages, 2012. DOI: 10.1016/S1567-5688(07)71750-6.

28. Andre R Duraes,Yasmin SL Bitar, Ana Carolina T Freitas, Ivan MP Filho, Beatriz C Freitas, Andre MS Fernandez.Gender differences in STelevation myocardial infarction (STEMI) time delays: experience of a public health service in Salvador-Brazil. Am J Cardiovasc Dis 2017;7(5):102-107. PMID:29181266. 